\title{
Template-Free Synthesis of an Interlocked Covalent Organic Molecular Cage
}

\author{
Danbo Wang, Lin Zhang, Yingjie Zhao* \\ College of Polymer Science and Engineering, Qingdao University of Science and Technology, Qingdao \\ 266042, P. R. China \\ [*] Corresponding Authors: yz@qust.edu.cn \\ Supporting Information \\ Table of contents
}

1. Materials and general methods

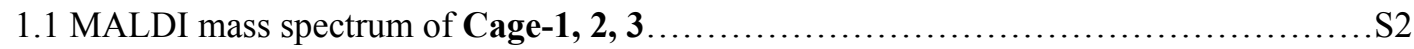

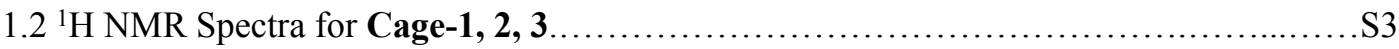

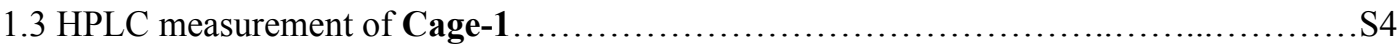

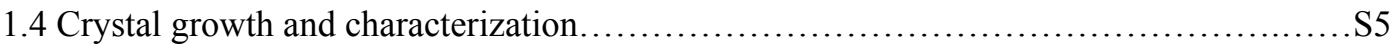

1.5 The single-crystal data of compound $\mathbf{5}$ and Cage-1, 2, 3............................. 6

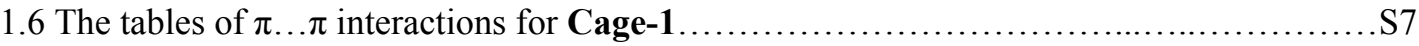

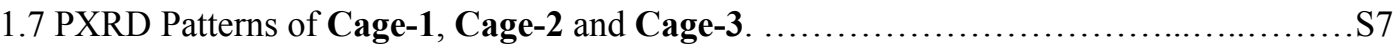

\section{Supporting Figures}

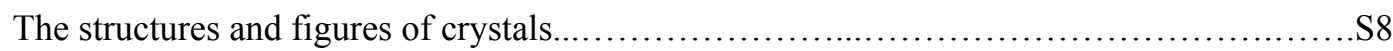




\section{Materials and general methods}

\subsection{MALDI mass spectrum of Cage-1, 2, 3}

Mass spectra were obtained on the Bruker Microflex LRF. MALDI analysis of Cage1, 2, 3 were carried out using DCTB as the matrix.
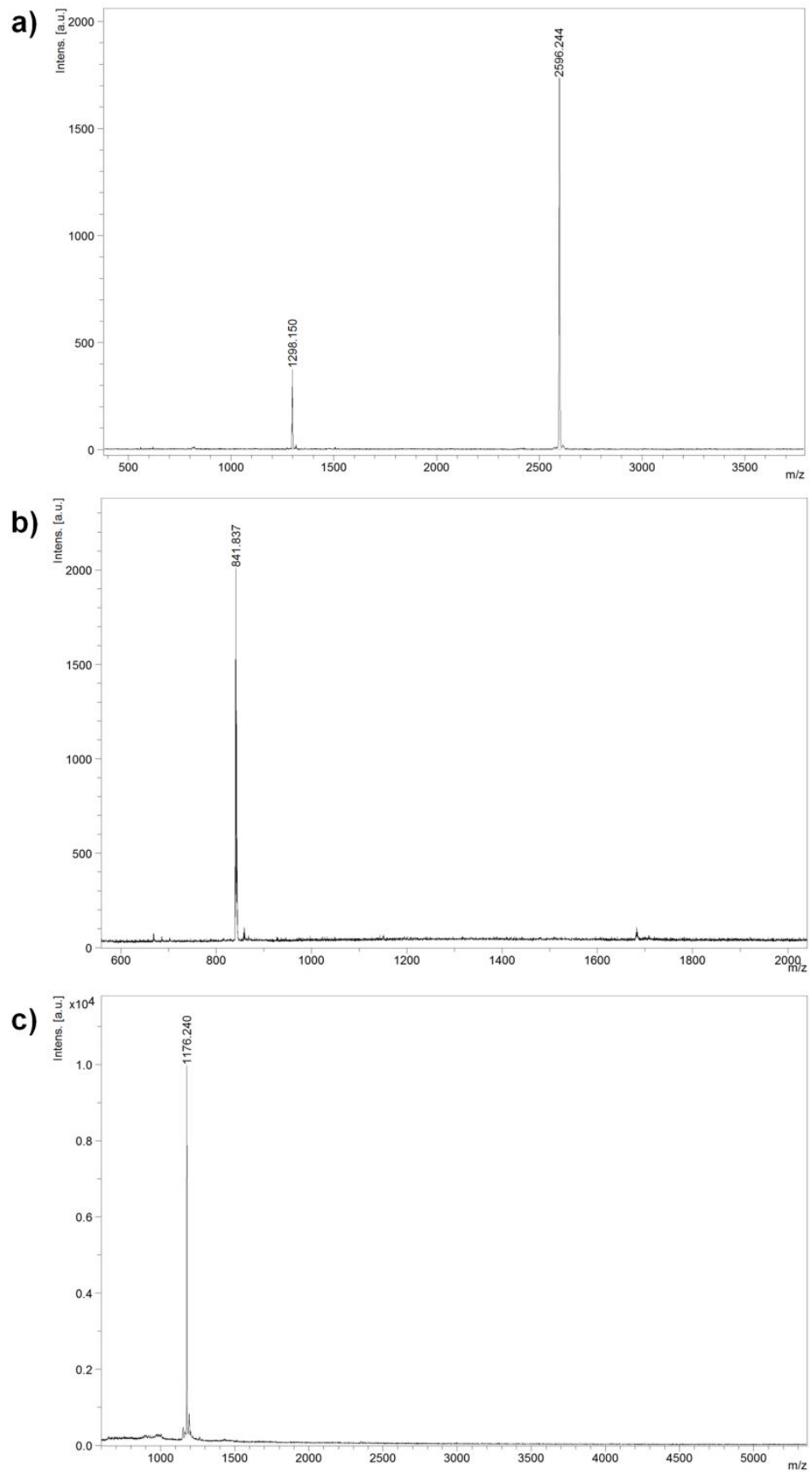

Figure S1. a) MALDI mass spectrum of Cage-1. b) MALDI mass spectrum of Cage2. c) MALDI mass spectrum of Cage-3. 


\section{2 ${ }^{1} \mathrm{H}$ NMR Spectra for Cage-1, 2, 3}

NMR spectra were taken on Bruker Magnet System $400 \mathrm{MHz}$ Ascend Nuclear Magnetic Resonance Spectrometer. DMSO (2.50 ppm) was used as internal references in ${ }^{1} \mathrm{H}$ NMR spectra. As for the complexity of configuration and interactions, the ${ }^{1}$ HNMR spectra of Cage-1 containing two partner cages are quite broad and complicated. In ${ }^{1} \mathrm{H}$ NMR spectra, the signals of all cage compounds are very weak due to their low solubility. ${ }^{13} \mathrm{C}$ NMR spectra are not available. 

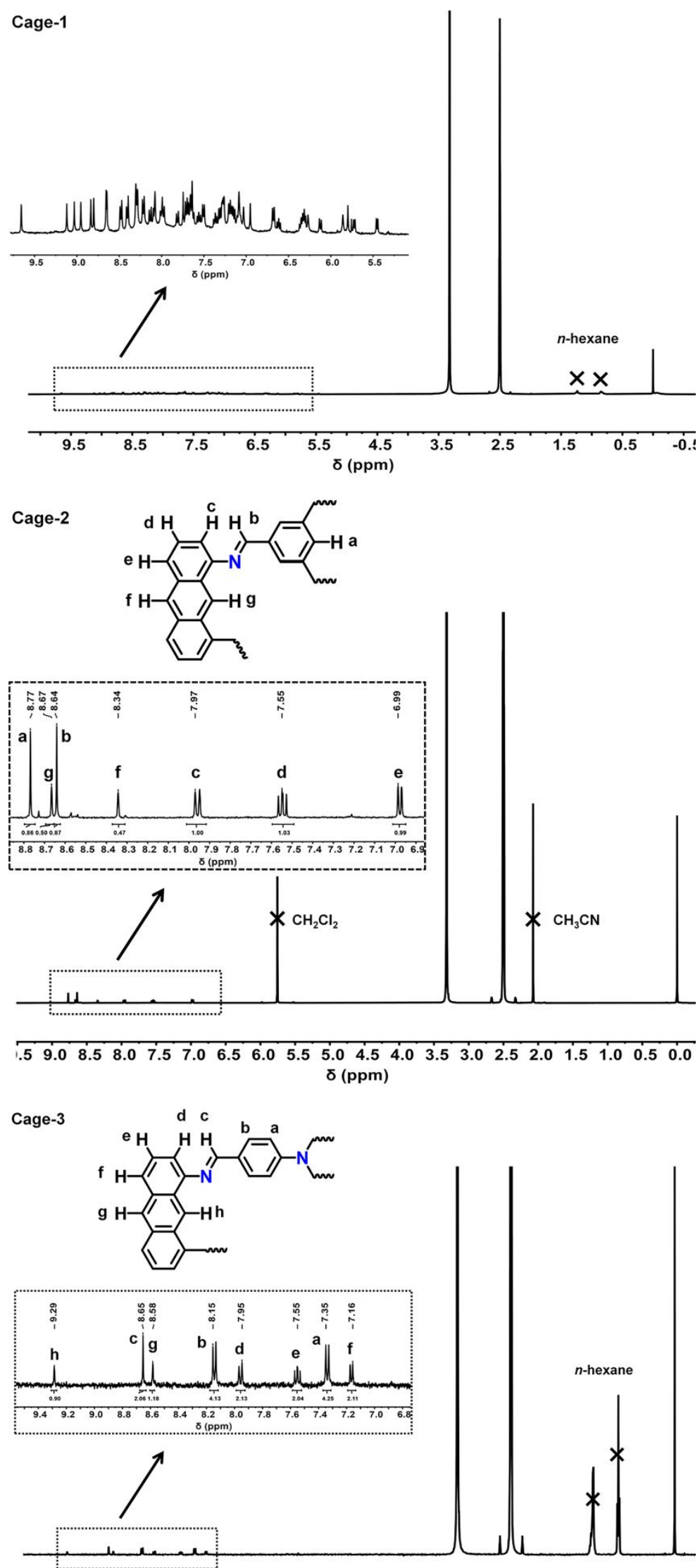

$\begin{array}{lllllllllllllllllllllll}9.5 & 9.0 & 8.5 & 8.0 & 7.5 & 7.0 & 6.5 & 6.0 & 5.5 & 5.0 & 4.5 & 4.0 & 3.5 & 3.0 & 2.5 & 2.0 & 1.5 & 1.0 & 0.5 & 0.0\end{array}$ $\delta(\mathrm{ppm})$

Figure S2. ${ }^{1} \mathrm{H}$ NMR Spectra for Cage-1, 2, 3 in DMSO- $d 6$ 


\subsection{HPLC measurement of Cage-1}

HPLC measurement was taken on WATERS-e2695 (Agilent XDB-C18 column). The column oven temperature was set to $28{ }^{\circ} \mathrm{C}$. A study on HPLC method for analyzing Cage-1 in the crude product was conducted by using tetrahydrofuran- acetonitrilemethanol-water (120:96:24:1) as mobile phase at a flow rate of $1 \mathrm{~mL} / \mathrm{min}$. The detection of HPLC analysis was conducted at $260 \mathrm{~nm}$. The purity of Cage-1 (95\%) and the content of Cage-1 in crude product (51\%) were determined by HPLC (XDB-C18, tetrahydrofuran- acetonitrile- methanol-water $=120: 96: 24: 1$, flow rate $=1.0 \mathrm{~mL} / \mathrm{min}, 1$ $=260 \mathrm{~nm}) \mathrm{tR}=10 \mathrm{~min}$.

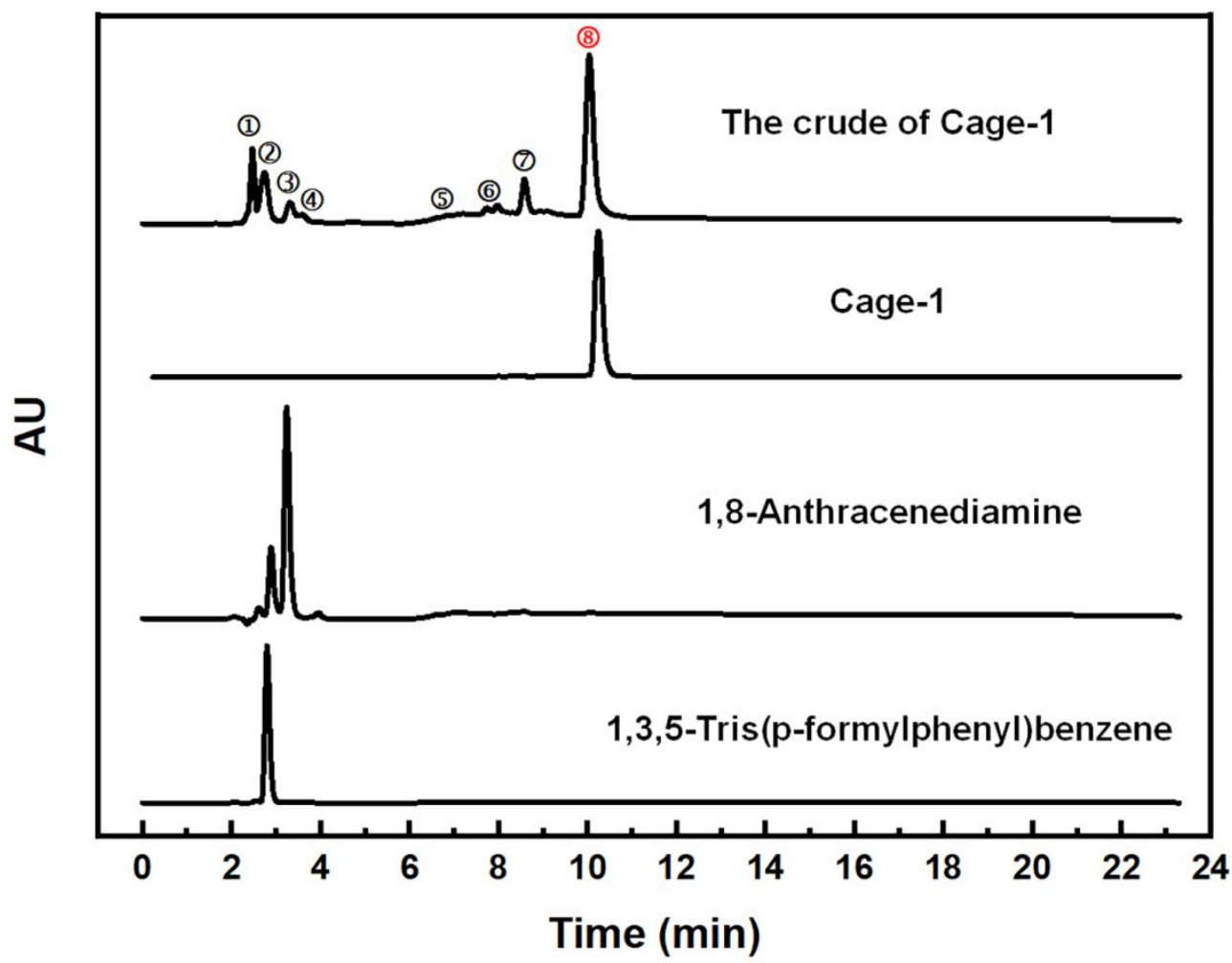

Figure S3. HPLC for compounds 1, 4, Cage-1 and the crude precipitate of Cage-1.

Table S1. HPLC data of the crude of Cage-1

\begin{tabular}{cccc}
\hline Number & Retention time (Min) & Area & Area (\%) \\
\hline (1) & 2.473 & 415231 & 12.03 \\
(2) & 2.744 & 516276 & 14.96 \\
(3) & 3.319 & 192655 & 5.58 \\
(4) & 3.581 & 66752 & 1.93
\end{tabular}




\begin{tabular}{cccc} 
(5) & 6.865 & 87275 & 2.53 \\
$(6)$ & 7.97 & 149863 & 4.34 \\
(7) & 8.585 & 276827 & 8.02 \\
(8) & 10.043 & 1746815 & 50.61 \\
Total & & 3451694 & 100 \\
\hline
\end{tabular}

\subsection{Crystal growth and characterization}

The single crystals of Cage-1, 2, 3 are successfully obtained through slow solvent diffusion. The interlocked Cage-1 is dissolved in $\mathrm{CH}_{2} \mathrm{Cl}_{2}$ first. Very slow diffusion of acetonitrile to the $\mathrm{CH}_{2} \mathrm{Cl}_{2}$ solution leads to the formation of a rhombic single crystal. For Cage-2 and Cage-3, the solvent systems of acetonitrile/ $\mathrm{CH}_{2} \mathrm{Cl}_{2}$ and 2cyanopyridine are adopted. For Cage-3, diffusion of acetonitrile to the pyridine solution also can obtain crystals. In addition, the crystal of reference compound $\mathbf{5}$ (triphenylbenzene) is gained by recrystallization in 1,4-dioxane. The crystal structures are performed in an X-ray diffractometer (XRD, X-Pert, PANalytic, Netherlands) with $\mathrm{Cu} \mathrm{K} \alpha$ radiation $(40 \mathrm{kV}, 30 \mathrm{~mA})$. CCDC $2107131-2107135$ contain the supplementary crystallographic data for this paper. The crystal structures were analyzed and refined by SHELX-program suite and OLEX2. 
1.5 The single-crystal data of compound 5 and Cage-1, 2, 3

Table S2. Crystal data and structure refinement.

\begin{tabular}{|c|c|c|c|c|c|}
\hline $\mathrm{CCDC}$ & 2107131 & 2107132 & 2107133 & 2107134 & 2107135 \\
\hline Name & Compound 5 & Cage-3 & Cage-2 & Cage-1 & Cage-3 \\
\hline $\begin{array}{l}\text { Identification } \\
\text { code }\end{array}$ & 32-wdb & tx5537_sq & tx5342b_sq & tx5020_sq & tx $5874 \mathrm{a}$ \\
\hline $\begin{array}{l}\text { Empirical } \\
\text { formula }\end{array}$ & $\mathrm{C}_{24} \mathrm{H}_{18}$ & $\begin{array}{l}\mathrm{C}_{84} \mathrm{H}_{54} \mathrm{~N}_{8}, \\
3\left(\mathrm{C}_{5} \mathrm{H}_{5} \mathrm{~N}\right)\end{array}$ & $\begin{array}{c}\mathrm{C}_{60} \mathrm{H}_{36} \mathrm{~N}_{6}, \\
\mathrm{C}_{2} \mathrm{H}_{3} \mathrm{~N}\end{array}$ & $\begin{array}{c}\mathrm{C}_{96} \mathrm{H}_{60} \mathrm{~N}_{6}, \\
\mathrm{C}_{2} \mathrm{H}_{3} \mathrm{~N}\end{array}$ & $\begin{array}{l}\mathrm{C}_{84} \mathrm{H}_{54} \mathrm{~N}_{8}, \\
6\left(\mathrm{C}_{6} \mathrm{H}_{4} \mathrm{~N}_{2}\right)\end{array}$ \\
\hline Temperature/K & 100 & 170 & 170 & 170 & 170 \\
\hline Space group & P n a $2{ }_{1}(33)$ & R -3 (148) & I 2/a (15) & P -1 (2) & P -1 (2) \\
\hline $\mathrm{a} / \AA$ & 7.4286 & 23.3274 & 25.6909 & 14.4822 & 15.7690 \\
\hline $\mathrm{b} / \AA$ & 19.7025 & 23.3274 & 14.9851 & 24.1592 & 16.5883 \\
\hline $\mathrm{c} / \AA ̊$ & 11.2004 & 30.3019 & 27.4407 & 25.3471 & 18.9818 \\
\hline$\alpha /^{\circ}$ & 90 & 90 & 90 & 89.345 & 105.0890 \\
\hline$\beta /{ }^{\circ}$ & 90 & 90 & 90.310 & 75.711 & 92.9220 \\
\hline$\gamma /{ }^{\circ}$ & 90 & 120 & 90 & 81.196 & 95.8130 \\
\hline Volume $/ \AA^{3}$ & $1639.31(11)$ & 14280.2 & 10564 & 8489.57 & 4753.95 \\
\hline Z & 4 & 6 & 8 & 4 & 2 \\
\hline $\begin{array}{c}\text { Data } \\
\text { completeness }\end{array}$ & 0.997 & 0.977 & 0.956 & 0.957 & 0.958 \\
\hline GooF & 1.088 & 1.059 & 1.051 & 1.048 & 1.076 \\
\hline $\mathrm{R}$ (reflections) & 0.0363 & 0.1023 & 0.0741 & 0.0673 & 0.0454 \\
\hline wR2(reflections) & 0.1018 & 0.2534 & 0.2456 & 0.2196 & 0.1328 \\
\hline
\end{tabular}




\subsection{The tables of $\pi . . . \pi$ interactions for Cage- 1}

Table S3. The tables of $\pi \ldots \pi$ interactions for Cage-1

\begin{tabular}{|c|c|c|c|}
\hline & & Interaction & $d_{\pi-\pi}(\AA)$ \\
\hline \multirow{3}{*}{$\begin{array}{l}\pi \text {-stacking } \\
\qquad \pi \ldots \pi \\
\text { interactions }\end{array}$} & \multirow{2}{*}{$\begin{array}{c}\text { Between } \\
\text { triphenylbenzene } \\
\text { units }\end{array}$} & Benzene $(\mathrm{C} 56 \mathrm{~A}-\mathrm{C} 61 \mathrm{~A}) \ldots$... Benzene $(\mathrm{C} 28-\mathrm{C} 33)$ & 3.37 \\
\hline & & Benzene $(\mathrm{C} 56-\mathrm{C} 61) \ldots$ Benzene (C28A-C33A) & 3.36 \\
\hline & $\begin{array}{l}\text { Between } \\
\text { anthracene units }\end{array}$ & $\begin{array}{c}\text { Benzene }(\mathrm{C} 76-\mathrm{C} 80, \mathrm{C} 89) \ldots \text { Benzene }(\mathrm{C} 76 \mathrm{~A}- \\
\text { C80A, C89A) }\end{array}$ & 3.53 \\
\hline \multirow{10}{*}{$\begin{array}{c}\text { T-shaped } \\
\qquad \pi \ldots \pi \\
\text { interactions }\end{array}$} & \multirow{6}{*}{$\begin{array}{c}\text { Between } \\
\text { triphenylbenzene } \\
\text { units }\end{array}$} & H34...Benzene (C62A-C67A) & 3.26 \\
\hline & & H20A...Benzene (C50-C55) & 2.82 \\
\hline & & H34A...Benzene (C62-C67) & 2.82 \\
\hline & & H20...Benzene (C50A-C55A) & 3.10 \\
\hline & & H70A...Benzene (C91-C96) & 3.00 \\
\hline & & H70...Benzene (C91A-C96A) & 3.30 \\
\hline & \multirow{4}{*}{$\begin{array}{l}\text { Between } \\
\text { triphenylbenzene } \\
\text { units and } \\
\text { anthracene units }\end{array}$} & H36...Benzene (C62A-C67A) & 3.12 \\
\hline & & H21A...Benzene (C39-C41, C46-C48) & 2.90 \\
\hline & & H21...Benzene ( C39A-C41A, C46A-C48A) & 2.89 \\
\hline & & H36A...Benzene (C62-C67) & 2.77 \\
\hline
\end{tabular}

\subsection{The single-crystal data of compound 5 and Cage-1, 2, 3}

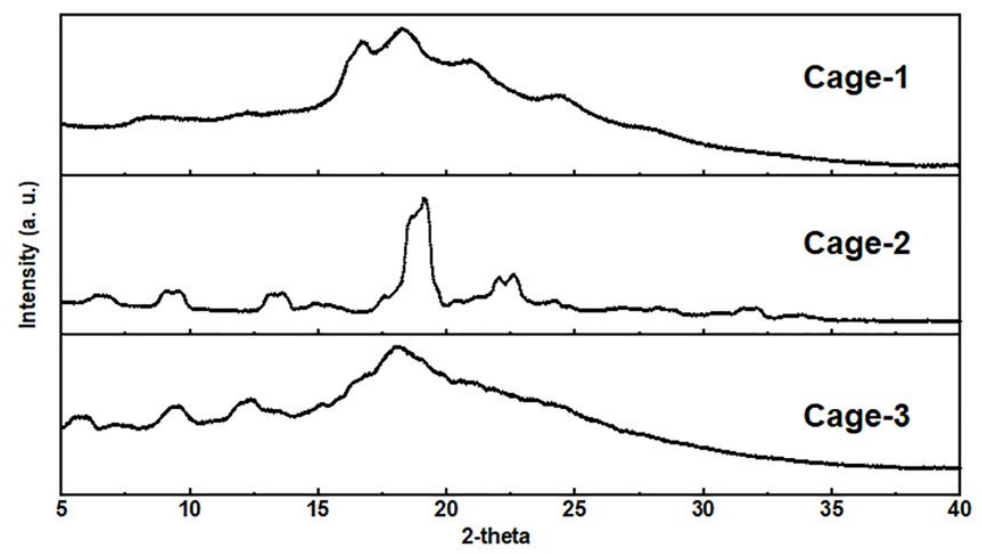

Figure S4. PXRD Patterns of Cage-1, Cage-2 and Cage-3. 


\section{Supporting Figures}
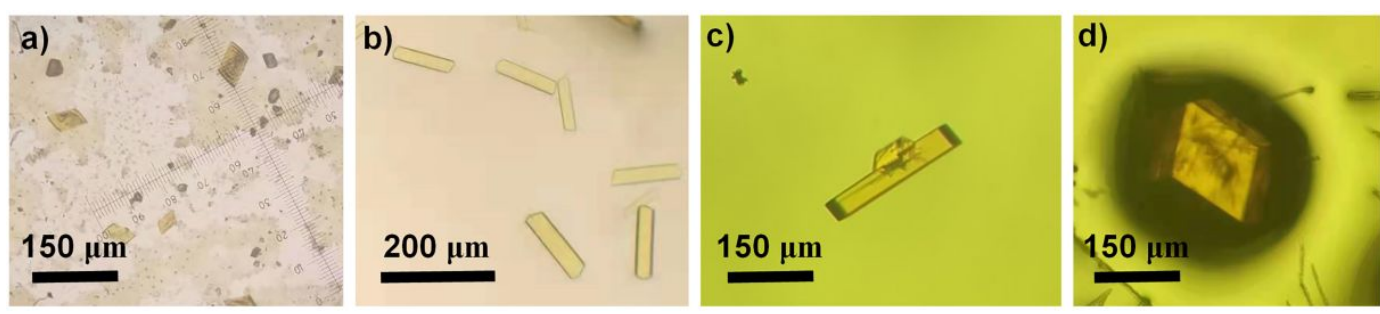

Figure S5. a) Optical microscope images of Cage-1, b) Cage-2, c) and d) Cage-3.
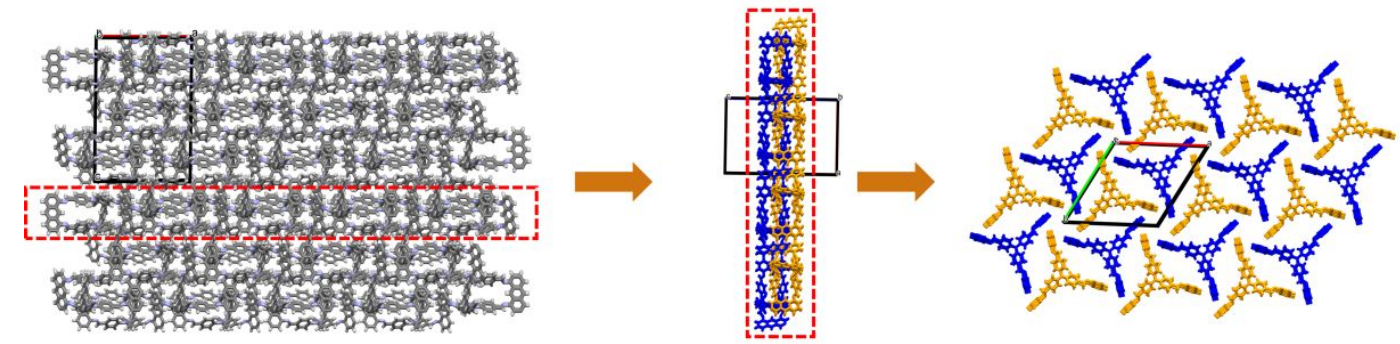

Figure S6. The packing modes in single crystals of Cage-3. The orange cages are in a layer and the blue are in another layer.
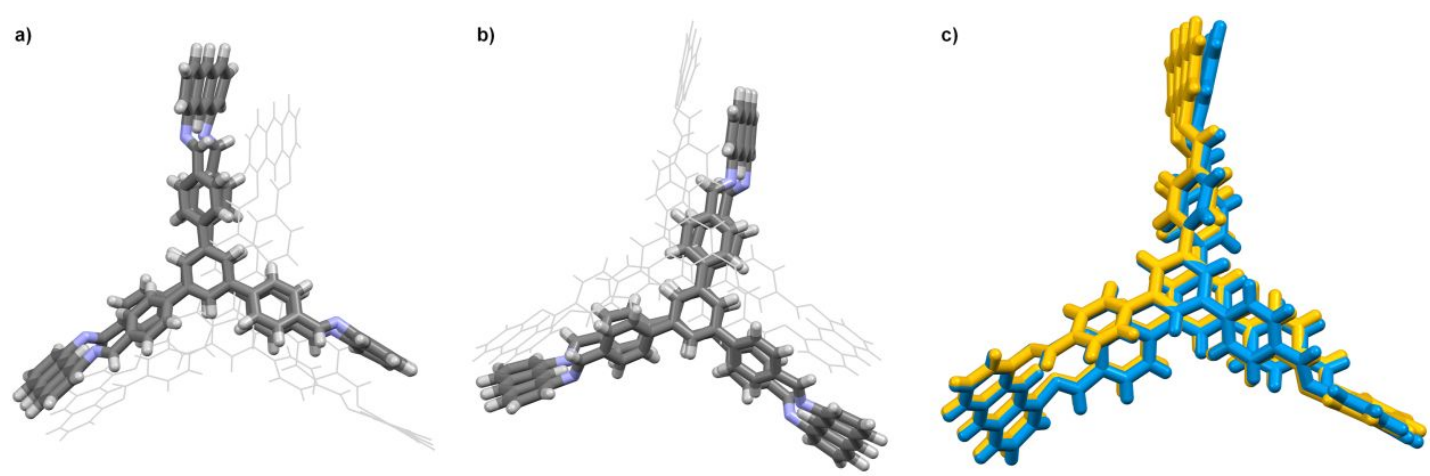

Figure S7. a) and b) The two partner cages in Cage-1. c) Moving the two partner cages to overlap by rotation and translation. 